\title{
POWER REGULATION BY COUPLE HALF WAVE LPWM RECTIFIER AT THREE-PHASE LOADS
}

\author{
Erol CAN
}

\begin{abstract}
The paper presents an application of power control by couple half wave LPWM rectifiers processing at the energy distribution line. The switching method with the components of semiconductor for alternating energy control in the energy distribution line is used on alternating energy sources. In three-phase power line and load, power control and regulation are done with the proposed modulation correction index $(\mathrm{MCl})$. Therefore, the simulation model of 3-phase energy distribution is established after the relationships between the energy sources and the circuit elements are determined by the circuit analysis method. The controls of the current and the voltage are done by trying at the different loads in the line at the simulation. According to the modulation correction index $(\mathrm{MCl})$, currents of unbalanced loads are balanced by the proposed method on the power line. Then, the balance currents and powers that $\mathrm{MCl}$ provides are calculated. Finally, a power line of $15 \mathrm{~km}$ at length that is created by connecting the model of RLC is tested. Obtained results show the effectiveness of the proposed method.
\end{abstract}

Keywords: balance currents; circuit analysis; modulation correction index; LPWM half rectifiers; simulation of power control

\section{INTRODUCTION}

As well as the production of energy, the distribution and use of existing energy is of great importance. Therefore, many studies have been conducted on energy production and distribution [1-3]. Direct current (DC) energy in power lines and different loads is controlled by converting it into changing energy with pulse width modulation (PWM) inverters [4-9]. Therefore, the DC power source is derived from either renewable energy sources or alternating current (AC) sources. The DC energy from the AC source is converted back into AC current to control the power line. The quality of the converted energy from the DC current decreases since the current and voltage contain a high amount of harmonic distortion [10-12]. Multi-level inverters are used to eliminate or reduce these unwanted effects. This increases the cost of the system and the complexity of the system while it makes it difficult to find the faults that can be on the device. In addition, for some loads on the line controlled by the multi-level inverter, the quality of the current can be drawn to the desired level while the voltage of the generated energy cannot be obtained at the desired level $[13,14]$. Thus, the paper presents a model of power control by inverse half rectifier processing method that uses the modulation correction index at an energy distribution line. On the line, there are two AC-source half-wave PWM rectifiers for each phase control current and voltage. Two GTO and two IGBT switches created are used on these half-wave rectifiers. This provides a mixed switches structure at the PWM rectifiers while it is intended for demonstrating the availability of different accessible switch preferences when performing energy control on the line. In the proposed control method, the effective values of the alternating current and voltage of the load are controlled by PWM on the load with dividing as the pulse width. Therefore, the modulation index values of PWM control the effective values of the current and voltage on the load without disturbing the sinus structures. In this study, the structure of the proposed line model is described with making the circuit analysis of the power line. After the design of the power line model, three-phase line operation is performed in MATLAB Simulink for different load cases in the application phase.

Then, obtained results of the simulation are verified in experimentation. The current and voltages of different loads without changing the sinus structure of current and voltage vary depending on the modulation index on the line. In the simulation conducted for unbalanced loads, the impedance of the third phase is half of the other phase impedances while the two phases are equal to each other. Imbalance current of the line with the low impedance value is balanced by regulating the modulation index value. These modulation index values are named as modulation correction index $(M C I)$ for balancing the power and current values in the first time. The imbalances due to different load conditions in the line are solved with different Modulation Correction Index values. These values are given in tables. When the results are analyzed, the value of the voltage controlled on the load has lower distortion than that of the previous line studies with inverters $[15,16]$. In addition, these results can be obtained in a less complicated and inexpensive way using the proposed model. In addition, according to the results, the power distribution line is simulated for efficient power distribution and control without losing a lot of time and money. Then, the results are validated in experimentation. By taking this model into consideration, applications can be performed in less time and with less error rate. As the missing and difficult sides of the power line in the simulation can be determined, the accidents and errors that may occur are reduced and the loss of life and property is eliminated at the experimentation. According to the results obtained, it is observed that energy distribution and control are done effectively. 


\section{DESIGN OF THE PROPOSED MODEL}

At three-phase power lines, six alternating energy sources are as $V_{\mathrm{s}}$, four of semiconductor switches are for every phase, one resistive load is for every phase, and parallel RL loads are connected in series to the resistive load for each phase. Four semiconductor switches used for each phase are 2-IGBT and 2-GTO at the applications. Linear Pulse Width Modulation method (LPWM) is used to control switches because LPWMs determine the operating time of the switches. The comparison of the triangular signals and the direct signal to generate LPWMs is as in Fig. 1b. Fig. 1a shows the power circuit. The power line seen in Fig. 1a consists of three balanced phases. The accounts to be made for a phase are valid for every phase at the line. The switches S3 and S4 provide a negative voltage of half-wave with the second Vs source on the load, while the switches S1 and S2 provide a positive voltage of half-wave with the first $V_{\mathrm{s}}$ source on the load. In this case, the sinus voltage and the sinus current are formed by dividing according to the duty ratio of the LPWM on the load as in Eq. (1). $\alpha$ is phase difference. $\omega t$ is electrical angle as radians.

$V_{\mathrm{s}}=U_{\mathrm{m}} \cdot \sin (\omega t)$

$D$ is the duty rate at which the PWMs are used to provide alternating sources over the load.

The alternating voltage that occurs on the line by two sources can be expressed as in Eq. (2).

$V_{\mathrm{s}}=D U_{\mathrm{m}} \cdot \sin (\omega t)$

The Z5 consists of a series of inductive $(L)$ and resistive $(R)$ loads. The unit of $R$ is expressed in ohm, the unit of $L$ in Henry, and the unit of Z6 in ohm.

$Z_{6}$ can be expressed as in Eq. (3).

$$
\frac{1}{Z_{6}}=\frac{1}{j \omega L}+\frac{1}{R}
$$

The $Z_{\mathrm{A}}$ is impedance of the first phase in ohm. $Z_{\mathrm{A}}$ can be expressed as in Eq. (4).

$$
Z_{\mathrm{A}}=Z_{6}+R_{1}
$$

The $I_{1}$ is current of the first phase in ampere. $I_{1}$ can be expressed as in Eq. (5).

$$
I_{1}=\frac{D U_{\mathrm{m}} \cdot \sin (\omega t)}{Z_{\mathrm{A}}}
$$

The $Z_{\mathrm{B}}$ is impedance of the second phase in ohm, The $Z_{\mathrm{C}}$ is impedance of the third phase in ohm. In the case of a balanced line, for voltages that have difference as the alphadegree of phase, the current of the second and third phases of the line is found as in Eq. (6) and in Eq. (7).

$$
\begin{aligned}
& I_{2}=\frac{D U_{\mathrm{m}} \cdot \sin (\omega t+\alpha)}{Z_{\mathrm{B}}} \\
& I_{3}=\frac{D U_{\mathrm{m}} \cdot \sin (\omega t+2 \alpha)}{Z_{\mathrm{C}}}
\end{aligned}
$$

If the B phase impedance is equal to half of the other phases, the operating times of the PWMs can be adjusted by calculating the Modulation Correction Index (MCI) to compensate for the current of the three phases.

$D_{1}$ is modulation index for C phase; $D_{2}$ is modulation index for $\mathrm{B}$ phase $(\mathrm{MCI})$ and is calculated as shown below.

$$
\begin{aligned}
& \frac{D_{1} U_{\mathrm{m}} \cdot \sin (\omega t+2 \alpha)}{Z_{\mathrm{C}}}=\frac{D_{2} U_{\mathrm{m}} \cdot \sin (\omega t+\alpha)}{Z_{\mathrm{B}}} \\
& \left\{\begin{array}{l}
Z_{\mathrm{C}}=2 Z_{\mathrm{B}} \\
U_{\mathrm{m}} \cdot \sin (\omega t+\alpha)=U_{\mathrm{m}} \cdot \sin (\omega t+2 \alpha)
\end{array}\right\} \\
& \frac{D_{1} U_{\mathrm{m}} \cdot \sin (\omega t+2 \alpha)}{Z_{\mathrm{C}}}=\frac{D_{2} U_{\mathrm{m}} \cdot \sin (\omega t+\alpha)}{2 Z_{\mathrm{C}}}
\end{aligned}
$$

$2 D_{1}=D_{2}$

$$
\left\{\begin{array}{l}
M C I=D_{1}-D_{2} \\
M C I=D_{1}-\frac{D_{1}}{2} \\
M C I=\frac{D_{1}}{2}
\end{array}\right\}
$$

The modulation index of the unbalanced line according to the calculated $M C I$ value should be increased as half the modulation index value of the $\mathrm{C}$ phase. The length of the power distribution line shall be determined as series resistance $\left(R_{\mathrm{L}}\right)$, inductance $\left(L_{\mathrm{L}}\right)$, capacitor $\left(C_{\mathrm{C}}\right)$ loads to be connected serially to the circuit in Fig. 1.

The $Z_{\mathrm{W}}$ represents the line length impedance. $Z_{\mathrm{W}}$ is described as in Eq. (13).

$Z_{\mathrm{W}}=j \omega L_{\mathrm{L}}+R_{\mathrm{L}}+\frac{1}{j \omega C_{\mathrm{C}}}$

Impedance $\left(Z_{\mathrm{L}}\right)$ of the power distribution line can be found as in Eq. (14).

$$
Z_{\mathrm{L}}=Z_{\mathrm{A}}+Z_{\mathrm{W}}
$$




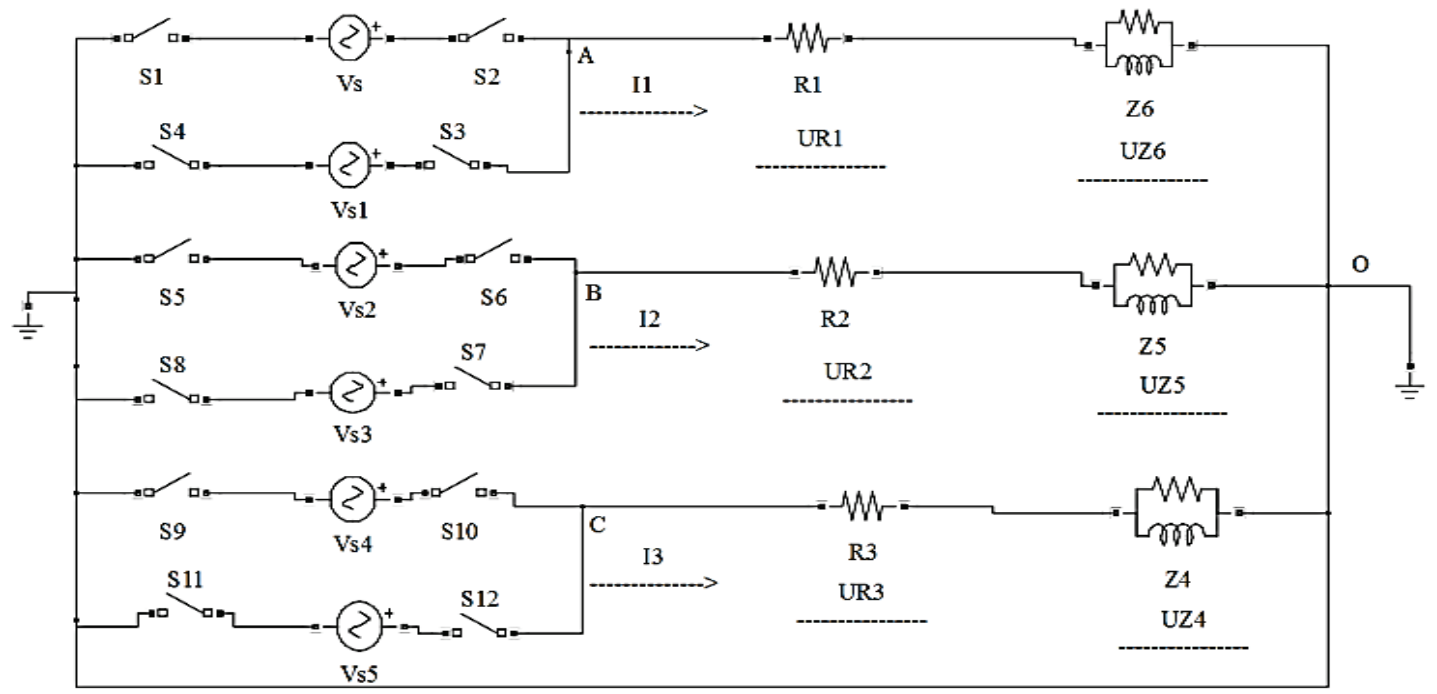

a)

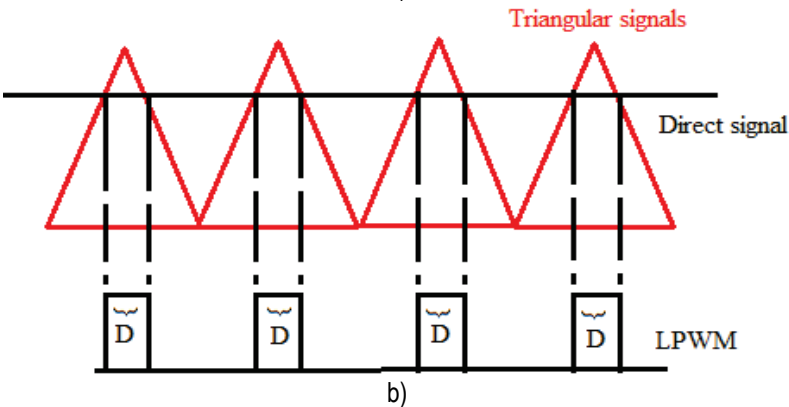

Figure 1 a) the power line of circuit model, b) LPWM

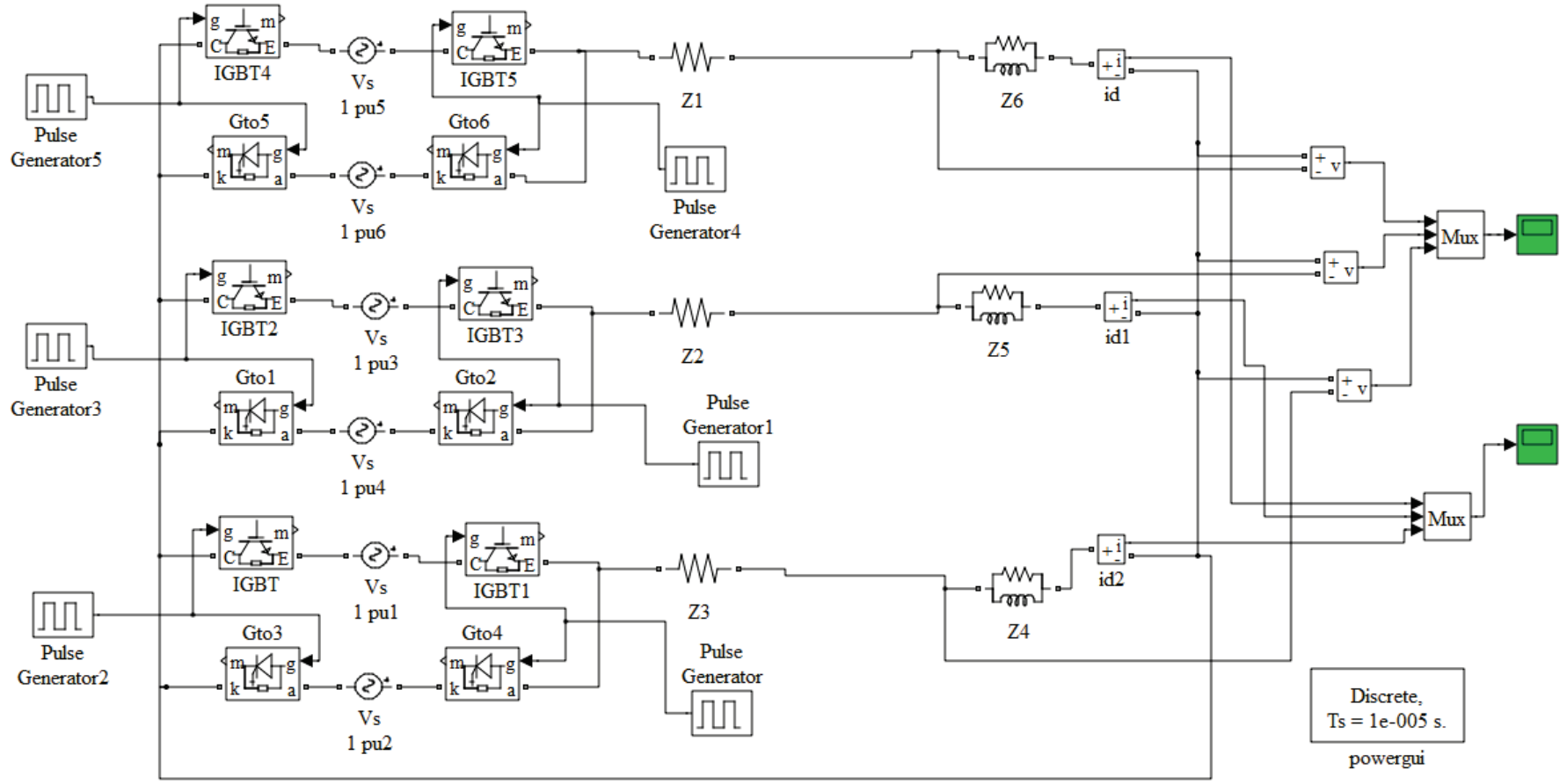

Figure 2 Balanced power line

\section{POWER LINE APPLICATION}

The impedances of each phase are equal to each other for the application in Fig. 2. $\mathrm{Z} 1=\mathrm{Z} 2=\mathrm{Z} 3=10 \mathrm{ohm}, \mathrm{Z} 6=\mathrm{Z} 5=$
$\mathrm{Z} 4=10+j 0.1, V_{\mathrm{s}}=220$ volt, Modulation index $=0.95$, Switching frequency is $100 \mathrm{kHz}$.

The circuit in Fig. 2 provides a three-phase alternating voltage at $60 \mathrm{~Hz}$ of frequency to the power line. The voltage 
and distortion value of voltage are given in Fig. 3, while the current is as in Fig. 4.

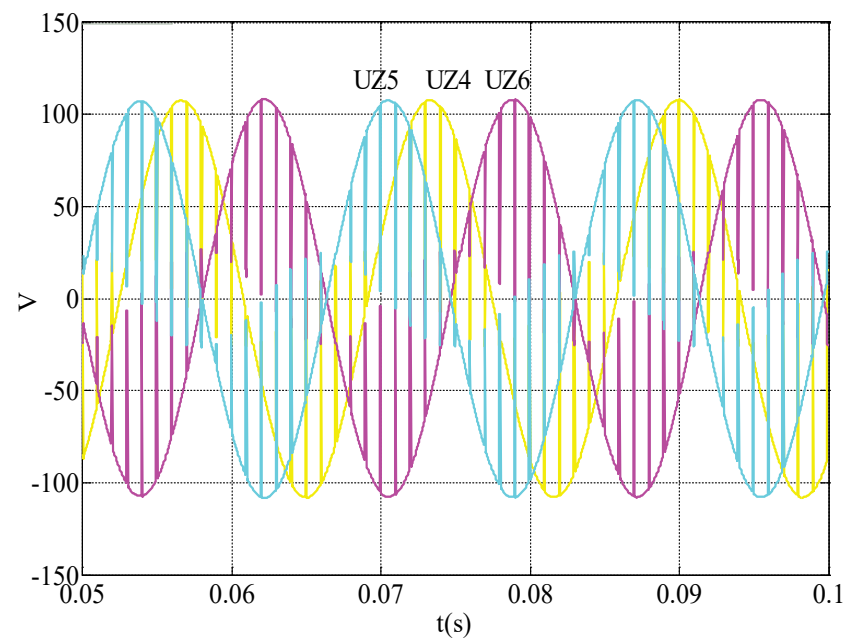

a)
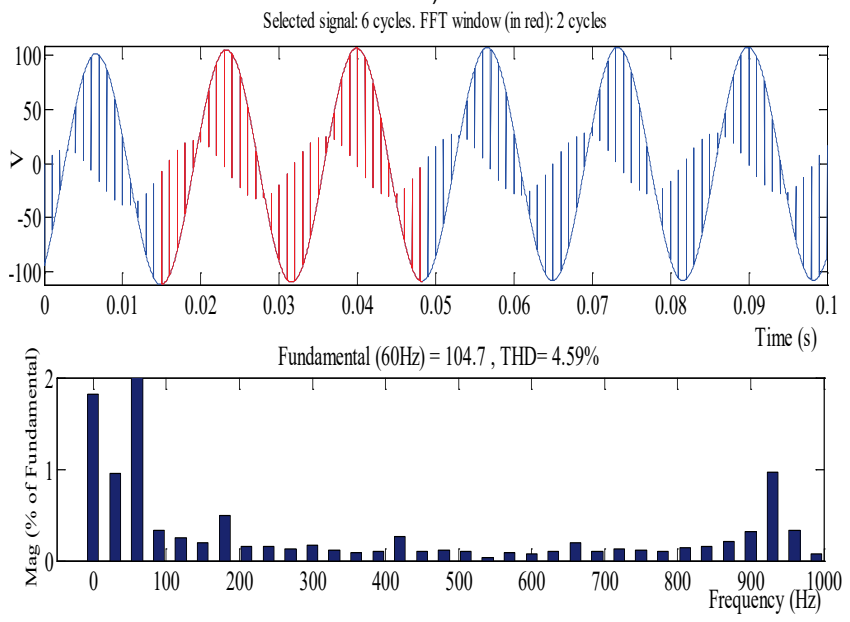

b)

Figure 3 a) 3-phase alternating voltage at $60 \mathrm{~Hz}$ of frequency, b) distortion value of voltage

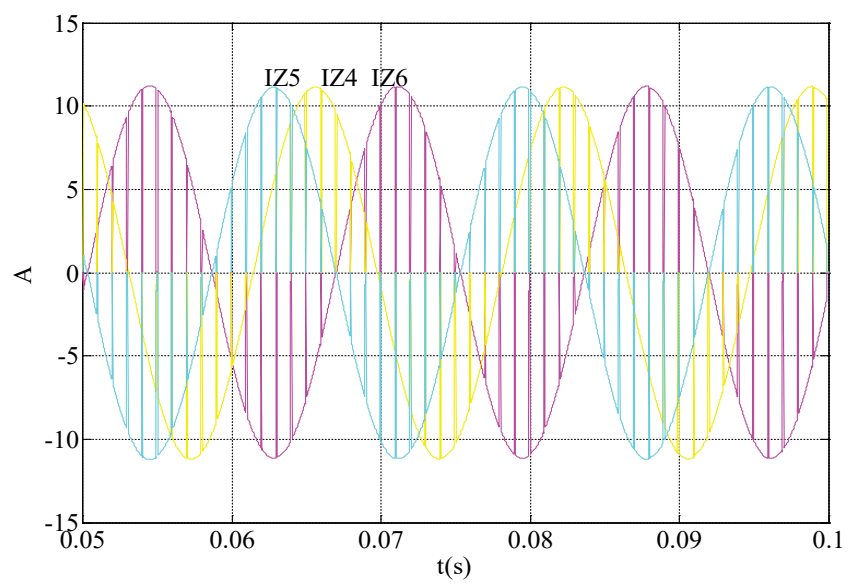

Figure 4 3-phase alternating current at $60 \mathrm{~Hz}$ of frequency for balanced load

For the balanced three-phase loads that are Z4, Z5, Z6 in Fig. 3a, a three-phase alternating voltage with 60 degree of the phase difference is provided on load. These voltages are formed on the load according to arranging the modulation index value. In Fig. 3b, the THD value of the voltage on the load is $4.49 \%$. $104.7 \mathrm{~V}$ is created with 0.95 of modulation index on load. While the THD values of the voltage supplied to the load with PWM inverters can exceed $100 \%$, a level of $4.59 \%$ can be achieved for the proposed method. In the simulation, the current obtained is given at the 0.8 of modulation index in Fig. 4.

For the balanced three-phase load that is ZA, ZB, ZC in Fig. 4, a three-phase alternating current with $60^{\circ}$ of the phase difference is provided on load. $10.7 \mathrm{~A}$ is created with 0.95 of modulation index on load. If loads in Fig. 2 are changed as $\mathrm{Z} 1=\mathrm{Z} 3=10 \mathrm{ohm}$ and $\mathrm{Z} 2=5 \mathrm{ohm} ; \mathrm{Z} 5$ and $\mathrm{Z} 4$ are $10+j 0.1$, $\mathrm{Z} 6=5+j 0.05$. $D$ is 0.8 . Then, three phases are unbalanced. Model is performed according to unbalanced loads; loads currents are shown in Fig. 5.

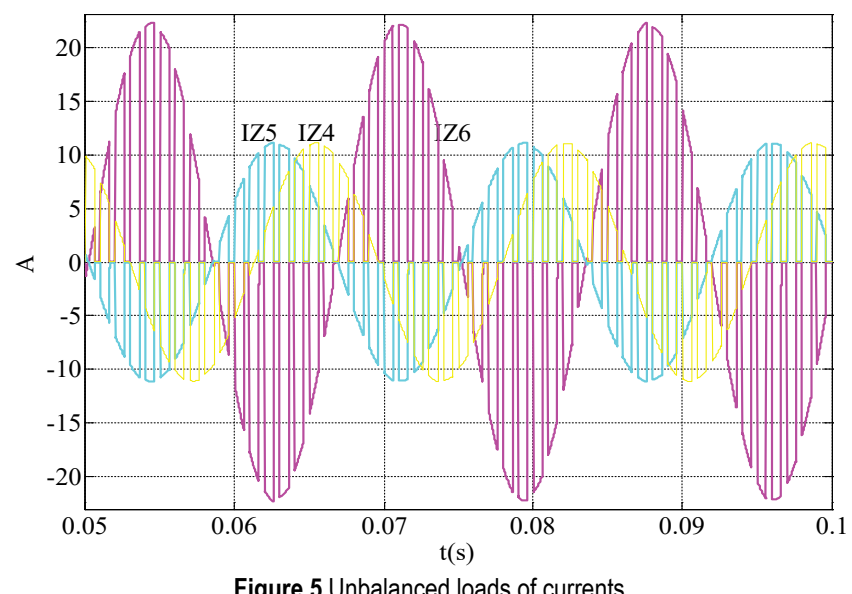

The load at less impedance value generates more current. Currents of IZ5 and IZ4 are 12 A at the maximum while Currents of IZ6 is 24A at the maximum. The difference in impedances of the loads is half. Therefore, the load with a low impedance of the modulation index must be twice the load with high impedance. Fig. 6 shows the balanced loads with the effective value of their current.

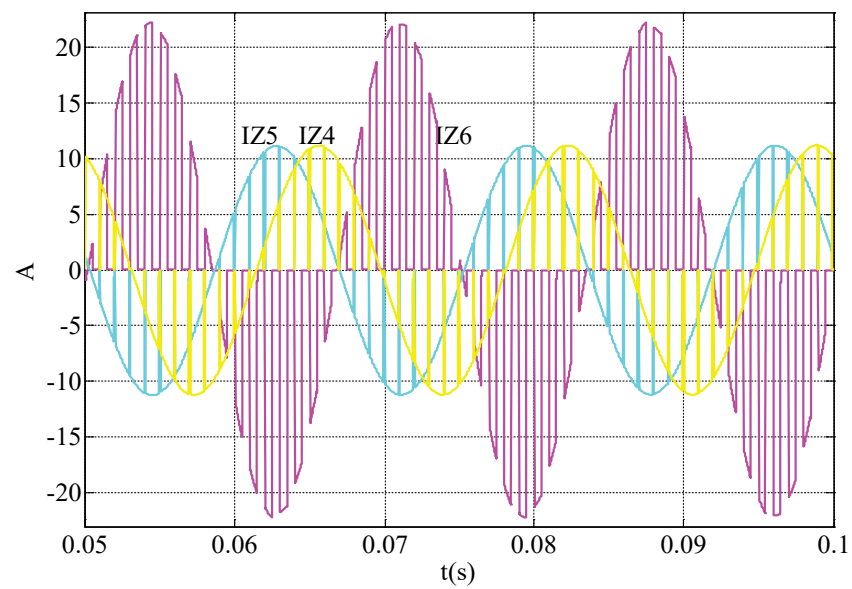

Figure 6 The balanced loads with the effective value of their current

MCI is 0.5 according to Eq. 11 . Therefore, when the modulation index for IZ6 is made to 0.45 , the modulation 
index for IZ4 and IZ5 is 0.9 . Then, IZ4 $=\mathrm{IZ} 5=\mathrm{IZ6}=10.8 \mathrm{~A}$ for effective value of the current [7].

When the three-phase line is supplied with 220 volts; balancing currents and MCIs are given in Tab. 1 for different line imbalances. When the three-phase line is supplied with 330 volts; balancing currents and MCIs are given in Tab. 2 for different line imbalances. $\mathrm{Z}$ is $10 \mathrm{ohms}$ as impedances.

Table 1 Correction currents and MCls of 3-phase lines fed with AC sources of 220V

\begin{tabular}{|c|c|c|c|c|c|c|c|}
\hline D & $\mathrm{ZA}$ & ZB & $\mathrm{ZC}$ & MCI & $\mathrm{I}_{\max }-\mathrm{I}_{\mathrm{ef}}$ for $\mathrm{I}_{\mathrm{ZA}}$ and $\mathrm{I}_{\mathrm{ZC}}$ & $\mathrm{I}_{\max }-\mathrm{I}_{\mathrm{ef}}$ for $\mathrm{I}_{\mathrm{ZB}}$ & $\mathrm{I}_{\mathrm{ef}}$ for $\mathrm{I}_{\mathrm{ZA}}$ and $\mathrm{I}_{\mathrm{ZC}}$ with MCI \\
\hline 0.8 & $\mathrm{Z}$ & $0.9 \mathrm{Z}$ & $\mathrm{Z}$ & 0.89 & $22 \mathrm{~A}-17.6 \mathrm{~A}$ & $24.4 \mathrm{~A}-19.6 \mathrm{~A}$ & $19.6 \mathrm{~A}$ \\
\hline 0.8 & $\mathrm{Z}$ & $0.8 \mathrm{Z}$ & $\mathrm{Z}$ & 0.99 & $22 \mathrm{~A}-17.6 \mathrm{~A}$ & $27.5 \mathrm{~A}-22 \mathrm{~A}$ & $22 \mathrm{~A}$ \\
\hline 0.7 & $Z$ & $0.9 \mathrm{Z}$ & $Z$ & 0.776 & $22 \mathrm{~A}-15.4 \mathrm{~A}$ & $24.4 \mathrm{~A}-17.08 \mathrm{~A}$ & $17.08 \mathrm{~A}$ \\
\hline 0.7 & $\mathrm{Z}$ & $0.8 \mathrm{Z}$ & $\mathrm{Z}$ & 0.875 & $22 \mathrm{~A}-15.4 \mathrm{~A}$ & $27.5 \mathrm{~A}-19.25 \mathrm{~A}$ & $19.25 \mathrm{~A}$ \\
\hline 0.7 & $\mathrm{Z}$ & $0.7 \mathrm{Z}$ & $\mathrm{Z}$ & 0.99 & $22 \mathrm{~A}-15.4 \mathrm{~A}$ & $31.42 \mathrm{~A}-22 \mathrm{~A}$ & $22 \mathrm{~A}$ \\
\hline 0.7 & $\mathrm{Z}$ & $0.6 \mathrm{Z}$ & $\mathrm{Z}$ & $\mathrm{X}$ & $22 \mathrm{~A}-15.4 \mathrm{~A}$ & $36.6 \mathrm{~A}-25.66 \mathrm{~A}$ & $\mathrm{X}$ \\
\hline 0.6 & $\mathrm{Z}$ & $0.9 \mathrm{Z}$ & $\mathrm{Z}$ & 0.666 & $22 \mathrm{~A}-13.2 \mathrm{~A}$ & $24.4 \mathrm{~A}-14.66 \mathrm{~A}$ & $14.66 \mathrm{~A}$ \\
\hline 0.6 & $\mathrm{Z}$ & $0.8 \mathrm{Z}$ & $\mathrm{Z}$ & 0.756 & $22 \mathrm{~A}-13.2 \mathrm{~A}$ & $27.5 \mathrm{~A}-16.65 \mathrm{~A}$ & $16.65 \mathrm{~A}$ \\
\hline 0.6 & $\mathrm{Z}$ & $0.7 \mathrm{Z}$ & $\mathrm{Z}$ & 0.857 & $22 \mathrm{~A}-13.2 \mathrm{~A}$ & $31.42 \mathrm{~A}-18.85 \mathrm{~A}$ & $18.85 \mathrm{~A}$ \\
\hline 0.6 & $\mathrm{Z}$ & $0.6 \mathrm{Z}$ & $\mathrm{Z}$ & 0.99 & $22 \mathrm{~A}-13.2 \mathrm{~A}$ & $36.66 \mathrm{~A}-22 \mathrm{~A}$ & $22 \mathrm{~A}$ \\
\hline 0.6 & $\mathrm{Z}$ & $0.5 \mathrm{Z}$ & $\mathrm{Z}$ & $\mathrm{X}$ & $22 \mathrm{~A}-13.2 \mathrm{~A}$ & $44 \mathrm{~A}-26.4 \mathrm{~A}$ & $\mathrm{X}$ \\
\hline 0.6 & $\mathrm{Z}$ & $0.4 \mathrm{Z}$ & $\mathrm{Z}$ & $\mathrm{X}$ & $22 \mathrm{~A}-13.2 \mathrm{~A}$ & $55-33 \mathrm{~A}$ & $\mathrm{X}$ \\
\hline
\end{tabular}

Table 2 Correction currents and MCls of 3-phase lines fed with AC sources of $330 \mathrm{~V}$

\begin{tabular}{|c|c|c|c|c|c|c|c|}
\hline $\mathrm{D}$ & $\mathrm{ZA}$ & ZB & $\mathrm{ZC}$ & MCI & $\mathrm{I}_{\max }-\mathrm{I}_{\mathrm{ef}}$ for $\mathrm{I}_{\mathrm{ZA}}$ and $\mathrm{I}_{\mathrm{ZC}}$ & $\mathrm{I}_{\max }-\mathrm{I}_{\mathrm{ef}}$ for $\mathrm{I}_{\mathrm{ZB}}$ & $\mathrm{I}_{\mathrm{ef}}$ for $\mathrm{I}_{\mathrm{ZA}}$ and $\mathrm{I}_{\mathrm{ZC}}$ with MCI \\
\hline 0.8 & $\mathrm{Z}$ & $0.9 \mathrm{Z}$ & $\mathrm{Z}$ & 0.89 & 33A-26.4A & $36.6 \mathrm{~A}-19.6 \mathrm{~A}$ & $29.4 \mathrm{~A}$ \\
\hline 0.8 & $\mathrm{Z}$ & $0.8 \mathrm{Z}$ & $\mathrm{Z}$ & 0.99 & $33 \mathrm{~A}-26.4 \mathrm{~A}$ & $41.25 \mathrm{~A}-33 \mathrm{~A}$ & $33 \mathrm{~A}$ \\
\hline 0.7 & $\mathrm{Z}$ & $0.9 \mathrm{Z}$ & $\mathrm{Z}$ & 0.776 & $33 \mathrm{~A}-23.1 \mathrm{~A}$ & $36.6 \mathrm{~A}-25.62 \mathrm{~A}$ & $25.62 \mathrm{~A}$ \\
\hline 0.7 & $\mathrm{Z}$ & $0.8 \mathrm{Z}$ & $\mathrm{Z}$ & 0.875 & $33 \mathrm{~A}-23.1 \mathrm{~A}$ & $41.25 \mathrm{~A}-28.87 \mathrm{~A}$ & $28.87 \mathrm{~A}$ \\
\hline 0.7 & $\mathrm{Z}$ & $0.7 \mathrm{Z}$ & $\mathrm{Z}$ & 0.99 & $33 \mathrm{~A}-23.1 \mathrm{~A}$ & $47.3 \mathrm{~A}-33 \mathrm{~A}$ & $33 \mathrm{~A}$ \\
\hline 0.7 & $\mathrm{Z}$ & $0.6 \mathrm{Z}$ & $\mathrm{Z}$ & $\mathrm{X}$ & $33 \mathrm{~A}-23.1 \mathrm{~A}$ & 54.9A-38.49A & $\mathrm{X}$ \\
\hline 0.6 & $\mathrm{Z}$ & $0.9 \mathrm{Z}$ & $\mathrm{Z}$ & 0.666 & 33A-19.8A & $36.6 \mathrm{~A}-21.99 \mathrm{~A}$ & $21.99 \mathrm{~A}$ \\
\hline 0.6 & $\mathrm{Z}$ & $0.8 \mathrm{Z}$ & $\mathrm{Z}$ & 0.756 & 33A-19.8A & $41.62 \mathrm{~A}-24.97 \mathrm{~A}$ & $24.97 \mathrm{~A}$ \\
\hline 0.6 & $\mathrm{Z}$ & $0.7 \mathrm{Z}$ & $\mathrm{Z}$ & 0.857 & 33A-19.8A & $47.13 \mathrm{~A}-28.27 \mathrm{~A}$ & $28.27 \mathrm{~A}$ \\
\hline 0.6 & $\mathrm{Z}$ & $0.6 \mathrm{Z}$ & $\mathrm{Z}$ & 0.99 & 33A-19.8A & $54.99 \mathrm{~A}-33 \mathrm{~A}$ & $33 \mathrm{~A}$ \\
\hline 0.6 & $\mathrm{Z}$ & $0.5 \mathrm{Z}$ & $\mathrm{Z}$ & $\mathrm{X}$ & 33A-19.8A & $66 \mathrm{~A}-39.6 \mathrm{~A}$ & $\mathrm{X}$ \\
\hline 0.6 & $Z$ & $0.4 Z$ & $\mathrm{Z}$ & $\mathrm{X}$ & 33A-19.8A & $82.5 \mathrm{~A}-44 \mathrm{~A}$ & $\mathrm{X}$ \\
\hline
\end{tabular}

Table 3 Balancing currents and balancing powers for three-phase system with 220 volt input

\begin{tabular}{|c|c|c|c|c|}
\hline \multicolumn{5}{|c|}{ Volt input } \\
\hline Impedance (Ohm) & MI & MCI & $\mathrm{Pb}(\mathrm{VA})$ & $\mathrm{I}_{\mathrm{b}}(\mathrm{A})$ \\
\hline $0.9 \mathrm{Z}$ & 0.8 & 0.89 & 440 & 2 \\
\hline $0.8 \mathrm{Z}$ & 0.8 & 0.99 & 968 & 4.4 \\
\hline $0.9 \mathrm{Z}$ & 0.7 & 0.776 & 309 & 1.68 \\
\hline $0.8 \mathrm{Z}$ & 0.7 & 0.875 & 847 & 3.85 \\
\hline $0.7 \mathrm{Z}$ & 0.7 & 0.99 & 1452 & 6.6 \\
\hline $0.6 \mathrm{Z}$ & 0.7 & $\mathrm{X}$ & $\mathrm{X}$ & $\mathrm{X}$ \\
\hline $0.9 \mathrm{Z}$ & 0.6 & 0.666 & 321,2 & 1.46 \\
\hline $0.8 \mathrm{Z}$ & 0.6 & 0.756 & 759 & 3.45 \\
\hline $0.7 \mathrm{Z}$ & 0.6 & 0.857 & 1243 & 5.65 \\
\hline $0.6 \mathrm{Z}$ & 0.6 & 0.99 & 1936 & 8.8 \\
\hline $0.5 \mathrm{Z}$ & 0.6 & $\mathrm{X}$ & $\mathrm{X}$ & $\mathrm{X}$ \\
\hline $0.4 \mathrm{Z}$ & 0.6 & $\mathrm{X}$ & $\mathrm{X}$ & $\mathrm{X}$ \\
\hline
\end{tabular}

In Tab. 1, the imbalances generated in the impedances ranging from $10 \mathrm{ohm}$ to $4 \mathrm{ohm}$ on the line are controlled by the modulation index that is from 0.8 to 0.6 . While the effective value of the line current is balanced twice in the 0.8 modulation index, the effective value of the line current can be set at three times for the 0.7 of modulation index value. In the case of 0.6 modulation index, the effective value of the line current can be compensated four times. For the $0.9 \mathrm{Z}$ value of $Z B$ at the 0.8 of the modulation index, the $\mathrm{MCI}$ value is 0.89 . For the $0.8 \mathrm{Z}$ value of $\mathrm{ZB}$ at the 0.8 of the modulation index, the $\mathrm{MCI}$ value is 0.99 . At the 0.7 of the modulation index, the MCI value is 0.776 for the $0.9 \mathrm{Z}$ value of $\mathrm{ZB}$ while the $\mathrm{MCI}$ value is 0.875 for the $0.8 \mathrm{Z}$ value of $\mathrm{ZB}$. The line can be balanced in nine of twelve trials, while the line cannot be balanced in three cases. Although a current of $25.6 \mathrm{~A}$ is required for the compensation of the line, the maximum current that the line can achieve is $22 \mathrm{~A}$ at 0.99 of modulation index. Current imbalance of the $6 \mathrm{ohm}$ of the impedance controlled by 0.7 modulation index cannot be compensated. Thus, MCI is shown with X. Although a current of $26.4 \mathrm{~A}$ is required for the compensation of the line, the maximum current that the line can achieve is $22 \mathrm{~A}$ at 0.99 of modulation index. Current imbalance of the $5 \mathrm{ohm}$ impedance controlled by 0.6 modulation index cannot be compensated. So, $\mathrm{MCI}$ is shown with $\mathrm{X}$ for it.

Although a current of $33 \mathrm{~A}$ is required for the compensation of the line, the maximum current that the line can achieve is $22 \mathrm{~A}$ at 0.99 of modulation index. Current imbalance of the $4 \mathrm{ohm}$ impedance controlled by 0.6 modulation index cannot be compensated. Thus, MCI is shown with $\mathrm{X}$ for it. In Tab. 2, the imbalances generated in the impedances ranging from $10 \mathrm{ohm}$ to $4 \mathrm{ohm}$ are controlled on the line from 0.8 modulation index to 0.6 modulation index. The line can be balanced in nine of twelve trials, while the line cannot be balanced in three cases. Tab. 3 shows the balancing current and balancing power generated by arranging of the MCI to compensate for the three-phase power line, which has $220 \mathrm{~V}$ of the input voltage source. Tab. 4 has the balancing current and balancing power generated by arranging of the MCI to compensate for the three-phase power line, which has $330 \mathrm{~V}$ of the input voltage source. The balance current $\left(I_{\mathrm{b}}\right)$ is the difference between the high phase 
current and the low phase current values. This value can be expressed as follows.

$$
\begin{aligned}
& I_{\mathrm{b}}=I_{\mathrm{ZA}}-I_{\mathrm{ZB}} \\
& I_{\mathrm{b}}=I_{\mathrm{ZA}}-I_{\mathrm{ZB}}
\end{aligned}
$$

The balance power $\left(P_{\mathrm{b}}\right)$ can be found as in Eq. (16) while $U_{\mathrm{i}}$ is input voltage for the line.

$$
P_{\mathrm{b}}=U_{\mathrm{i}} \cdot I_{\mathrm{b}}
$$

For the impedance of $0.9 \mathrm{Z}$ at Tab. 2, a compensation power of $440 \mathrm{VA}$ and a balancing current of $2 \mathrm{~A}$ are provided with a $0.89 M C I$ value when a compensation power of 968VA and a balancing current of $4.4 \mathrm{~A}$ are provided with a 0.99 of $M C I$. The first greatest balancing power and current are $1936 \mathrm{VA}$ and $8 \mathrm{~A}$ that are provided with 0.99 of $M C I$ at the $0.6 \mathrm{Z}$ of impedance, while the second greatest balancing power and current are $1452 \mathrm{VA}$ and $6.6 \mathrm{~A}$ that are provided with 0.99 of $M C I$ at $0.7 \mathrm{Z}$ of the impedance. When the impedance value $(Z)$ is $10 \mathrm{ohm}$, the balancing current and power cannot be provided with 0.6 of modulation index to the system supplied with 220 volts for $0.5 \mathrm{Z}$ and $0.4 \mathrm{Z}$ impedance values. When the impedance value $(Z)$ is $10 \mathrm{ohm}$, the balancing current and power cannot be provided with 0.7 of modulation index to the system supplied with $220 \mathrm{~V}$ for $0.6 \mathrm{Z}$ of the impedance values.

Table 4 Balancing currents and balancing powers for three-phase system with 330 volt input

\begin{tabular}{|c|c|c|c|c|}
\hline Impedance $(\mathrm{Ohm})$ & $M I$ & $M C I$ & $P_{\mathrm{b}}(\mathrm{VA})$ & $I_{\mathrm{b}}(\mathrm{A})$ \\
\hline $0.9 \mathrm{Z}$ & 0.8 & 0.89 & 880 & 4 \\
\hline $0.8 \mathrm{Z}$ & 0.8 & 0.99 & 1936 & 8.8 \\
\hline $0.9 \mathrm{Z}$ & 0.7 & 0.776 & 618 & 336 \\
\hline $0.8 \mathrm{Z}$ & 0.7 & 0.875 & 847 & 7.7 \\
\hline $0.7 \mathrm{Z}$ & 0.7 & 0.99 & 2904 & 13.2 \\
\hline $0.6 \mathrm{Z}$ & 0.7 & $\mathrm{X}$ & $\mathrm{X}$ & $\mathrm{X}$ \\
\hline $0.9 \mathrm{Z}$ & 0.6 & 0.666 & 642 & 2.92 \\
\hline $0.8 \mathrm{Z}$ & 0.6 & 0.756 & 1518 & 6.9 \\
\hline $0.7 \mathrm{Z}$ & 0.6 & 0.857 & 2486 & 11.3 \\
\hline $0.6 \mathrm{Z}$ & 0.6 & 0.99 & 3872 & 17.6 \\
\hline $0.5 \mathrm{Z}$ & 0.6 & $\mathrm{X}$ & $\mathrm{X}$ & $\mathrm{X}$ \\
\hline $0.4 \mathrm{Z}$ & 0.6 & $\mathrm{X}$ & $\mathrm{X}$ & $\mathrm{X}$ \\
\hline
\end{tabular}

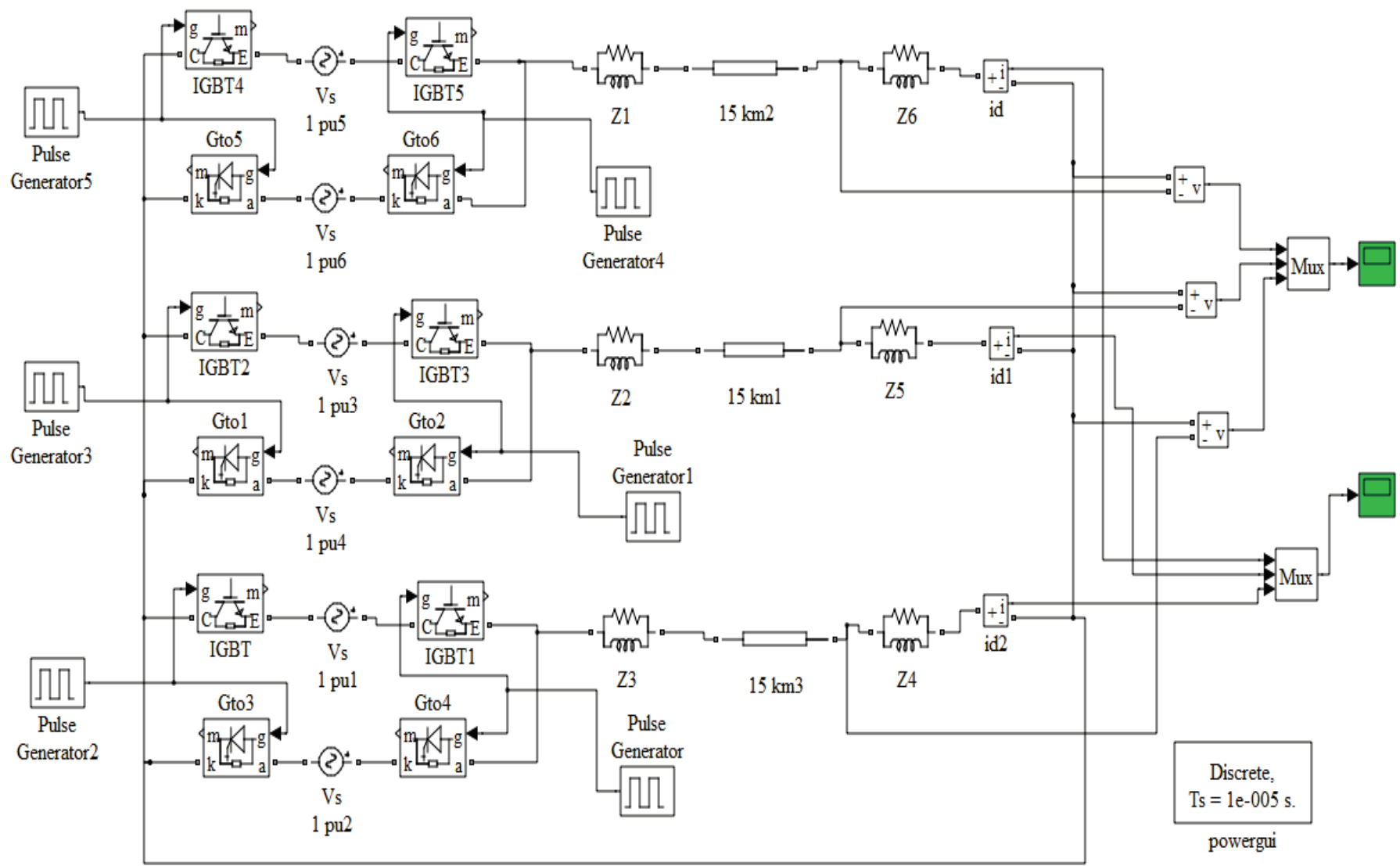

Figure 7 Regulated power line of $15 \mathrm{~km}$

For the impedance of $0.9 \mathrm{Z}$ at Tab. 4 , a compensation power of $880 \mathrm{VA}$ and a balancing current of $4 \mathrm{~A}$ are provided with a $0.89 M C I$ value when a compensation power of 968VA and a balancing current of $8.8 \mathrm{~A}$ are provided with a 0.99 of $M C I$. The first greatest balancing power and current are $3872 \mathrm{VA}$ and $8 \mathrm{~A}$ that are provided with 0.99 of $M C I$ at the $0.6 \mathrm{Z}$ of impedance, while the second greatest balancing power and current are $2904 \mathrm{VA}$ and 13.2 A that are provided with 0.99 of $M C I$ at $0.7 \mathrm{Z}$ of the impedance. As the unbalanced phase impedance decreases, the applied $M C I$ and the balancing current increase, which leads to an increase in the balancing power. When the 
impedance value $(\mathrm{Z})$ is $10 \mathrm{ohm}$, the balancing current and power cannot be provided with 0.6 of modulation index to the system supplied with $330 \mathrm{~V}$ for $0.5 \mathrm{Z}$ and $0.4 \mathrm{Z}$ impedance values. In line with the model in Figure 1, a line length of $15 \mathrm{~km}$ in Fig. 7 can be obtained if a serial RLC circuit is added to the series. $\mathrm{Z} 1=\mathrm{Z} 2=\mathrm{Z} 3=\mathrm{Z} 4=\mathrm{Z} 5=\mathrm{Z} 6$ $=10+j 0.1$.

$R, L, C$ values for the impedance of the line $\left(Z_{\mathrm{w}}\right)$ are respectively as $0.143 \mathrm{ohm}, 102 \times 10^{-2} \mathrm{H}, C=1510 \times 10^{-8}$. Regulated power line of $15 \mathrm{~km}$ is in Fig. 7.

Parallel RL loads connected in series at the beginning and end of the $15 \mathrm{~km}$ long line in Fig. 7 are energized by alternating power sources that are controlled by switches with 0.9 of modulation index. The three-phase alternating voltage that occurs at the end of the power line is as in Fig. $8 \mathrm{a}$, while the harmonic distortion of the voltage on the load is as in Fig. 8b.

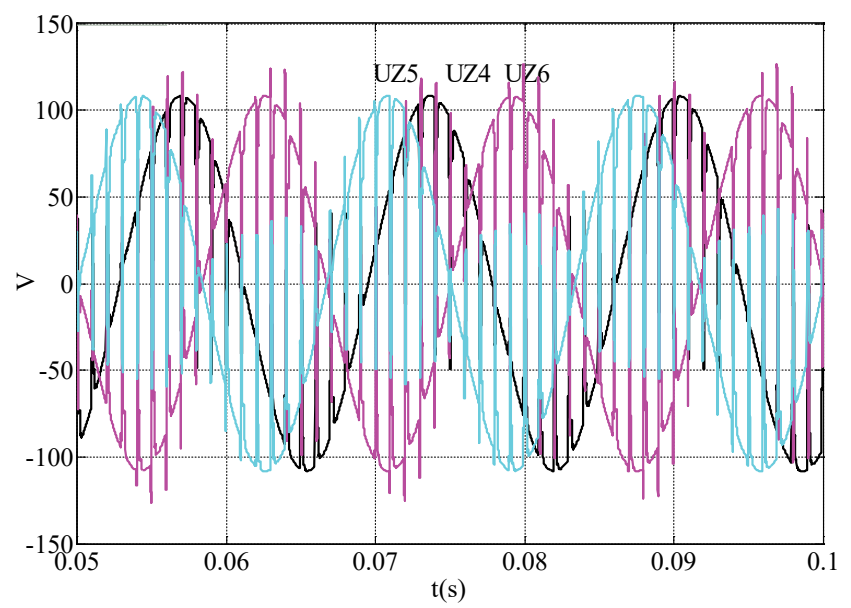

a)

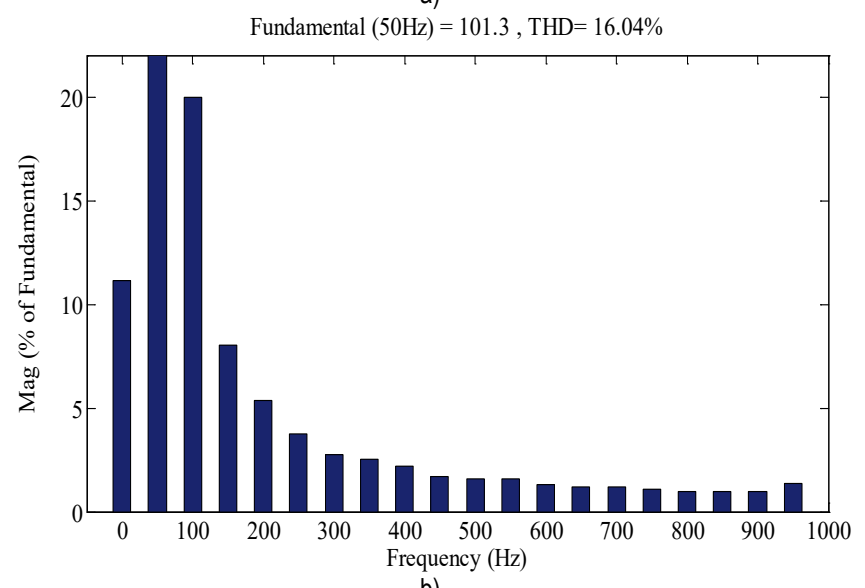

b)

Figure 8 a) The three-phase alternating voltage that occurs at the end of the line, b) the harmonic distortion of the voltage on the load

On the power line, 101 volts of the alternating voltage at the maximum value is formed on loads. The effective value of the voltage is $90.9 \mathrm{~V}$ because the modulation index is 0.9 . Although there is no filtering element on the line, the distortion of the load voltage is $16 \%$. If the load on such a line is provided with alternating voltage by conventional inverter methods, this value will exceed $100 \%$. When
Parallel RL loads connected in series at the beginning and end of the $15 \mathrm{~km}$ long line are energized with alternating source, a three-phase alternating current that occurs on the load is presented in Fig. 9.

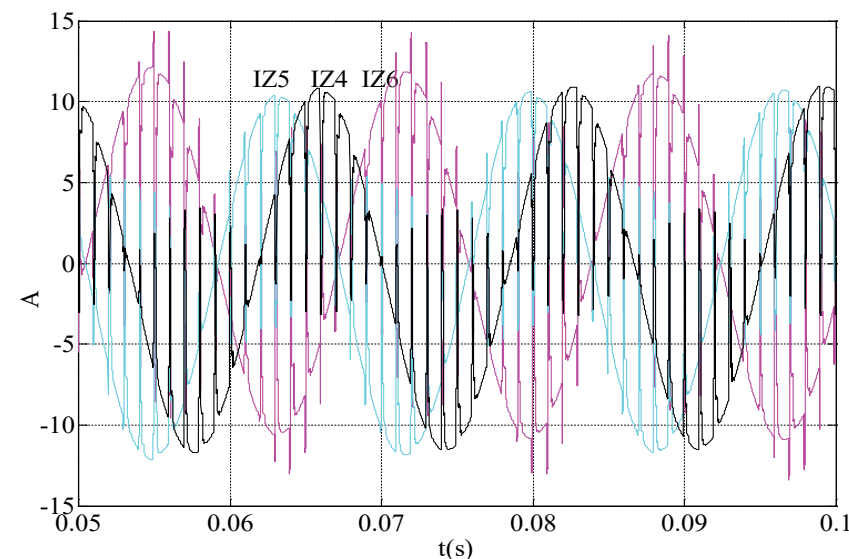

Figure $9 \mathrm{~A}$ three-phase alternating current of the $15 \mathrm{~km}$ long line

On the power line, a 12-volt alternating current at the maximum value is formed on loads. The effective value of the voltage is $10.2 \mathrm{~A}$ because the modulation index is 0.9 . According to the results, the power distribution line is simulated for efficient power distribution and control without losing a lot of time and money. By taking this model into consideration, applications can be performed in less time and with less error rate. As the missing and difficult sides of the power line in the simulation can be determined, the accidents and errors that may occur are reduced, and the loss of life and property is eliminated.

\section{CONCLUSION}

The paper presented power control by inverse half rectifier processing method at energy distribution line in the simulation. The three-phase power line was controlled by semiconductor switches in reverse and parallel connected sources for each phase. First, the circuit model and mathematical equations of the line were created. In mathematical equations, the effect of the modulation index of the control signals applied to the switches to the power occurring on the load was shown. In unbalanced loads, it was shown how to calculate the values of $M C I$ to equalize the effective value of the current. The current and voltage of the line were measured at different loads in the line. The balancing current and power were calculated by measuring for different modulation indices and line impedances. Obtained results and the effect of modulation index on the results were discussed. Unbalanced load current imbalances were eliminated by equalizing the effective values of the currents. As the unbalanced phase impedance decreases, the applied $M C I$ and the balancing current increase, which leads to an increase in the balancing power. According to the results obtained, the design and application of the line has been successfully achieved. 


\section{REFERENCES}

[1] Krauter, S. (2018). Simple and effective methods to match photovoltaic power generation to the grid load profile for a PV based energy system. Solar Energy, 159, 768-776. https://doi.org/10.1016/j.solener.2017.11.039

[2] Niu, B., Hwangbo, H., Zeng, L., \& Ding, Y. (2018). Evaluation of alternative power production efficiency metrics for offshore wind turbines and farms. Renewable Energy, 128, 81-90. https://doi.org/10.1016/j.renene.2018.05.050

[3] Exel, L. \& Frey, G. (2018). Modeling and simulation of local flexibilities and their effect to the entire power system. Computer Science-Research and Development, 33(12), 6. https://doi.org/10.1007/s00450-017-0346-7

[4] Matsumori, H., Shimizu, T., Takano, K., \& Ishii, H. (2018). Three-Phase AC Filter Inductor Design for Three-Phase PWM Inverter for Conversion Efficiency Improvement at Low Load. Electrical Engineering in Japan, 203(1), 37-49. https://doi.org/10.1002/eej.23053

[5] Ananda, A. S. (2018). Performance Analysis of Series-Passive Filter in 5-Phase PWM Inverter Drive and Harmonic Study Using Simulink/Matlab. In Advances in Power Systems and Energy Management (pp. 139-146). Springer, Singapore. https://doi.org/10.1007/978-981-10-4394-9_14

[6] Kumar, M. (2018). Time-Domain Characterization of Digitized PWM Inverter with Dead-Time Effect. IEEE Transactions on Circuits and Systems I: Regular Papers. https://doi.org/10.1109/TCSI.2018.2827950

[7] Mukherjee, S., Giri, S. K., Kundu, S., \& Banerjee, S. (2018). A Generalized Discontinuous PWM Scheme for Three-Level NPC Traction Inverter with Minimum Switching Loss for Electric Vehicles. IEEE Transactions on Industry Applications. https://doi.org/10.1109/TIA.2018.2866565

[8] Takahashi, H., Obara, H., \& Fujimoto, Y. (2018, March). Dead time compensation for three-level flying capacitor inverter with phase shift PWM. In Advanced Motion Control (AMC), 2018 IEEE 15th International Workshop on (pp. 229233). IEEE. https://doi.org/10.1109/AMC.2019.8371093

[9] Sivakumar, P., \& Arutchelvi, M. S. (2018). Modified composite power control strategy for grid connected wind-PV systems with unbalanced nonlinear current. International Transactions on Electrical Energy Systems, e2587. https://doi.org/10.1002/etep.2587

[10] Can, E., \& Sayan, H. H. (2016). SSPWM three phase inverter design and experimented on unbalanced loads. Tehnički vjesnik, 23(5), 1239-1244. https://doi.org/10.17559/TV-20150730222021

[11] Can, E. \& Sayan, H. H. (2017). The increasing harmonic effects of SSPWM multilevel inverter controlling load currents investigated on modulation index. Tehnički vjesnik, 24(2), 397-404. https://doi.org/10.17559/TV-20151020134629

[12] Can, E. (2018). The modeling and analysis of a power transmission line supplied by a solar power plant. Tehnički glasnik, 12(3), 124-130. https://doi.org/10.31803/tg-20180521111744

[13] Singh, S. N. \& Singh, G. K. (2017). Modelling, design and stability analysis of an improved SEPIC converter for renewable energy systems. International Journal of Electronics, 1-19.

[14] Pan, L., et al. (2017). One-cycle control for three-phase singlecapacitor Z-source inverter with unity power factor. International Journal of Electronics, 104(4), 635-658. https://doi.org/10.1080/00207217.2016.1242161
[15] Raj, N., Jagadanand, G., \& George, S. (2016). A Modified Charge Balancing Scheme for Cascaded H-Bridge Multilevel Inverter. Journal of Power Electronics, 16(6), 2067-2075. https://doi.org/10.6113/JPE.2016.16.6.2067

[16] Zheng, C. F., Zhang, B., Qiu, D. Y., Zhang, X. H., \& Xiao, L. M. (2015). Wavelet PWM Technique for Single-Phase ThreeLevel Inverters. Journal of Power Electronics, 15(6), 15171523. https://doi.org/10.6113/JPE.2015.15.6.1517

\section{Author's contacts:}

Erol CAN, PhD, Assoc. Prof. Aviation Electric Electronics, School of Civil Aviation, Erzincan Binali Yıldırım University, Fatih Avenue, 24100 Erzincan, Turkey cn_e@hotmail.com 